\title{
GUERRA. VÂNIA M. L. O INDÍGENA DE MATO GROSSO DO SUL: PRÁTICAS IDENTITÁRIAS E CULTURAIS. SÃO CARLOS: PEDRO \& JOÃO EDITORES, 140 PÁGINAS, 2010.
}

\author{
Resenhado por Elizabeth Fávero ${ }^{1}$ \\ (Universidade Federal de Mato Grosso do Sul-UFMS)
}

Vânia Maria Lescano Guerra, doutora em Linguística e Língua Portuguesa pela UNESP de Araraquara, com pós-doutoramento no Instituto de Estudos da Linguagem da UNICAMP, docente da Graduação e da Pós-Graduação da Universidade Federal de Mato Grosso do Sul e pesquisadora prolífera da Análise do Discurso, traz, em sua obra $O$ indígena de Mato Grosso do Sul: práticas identitárias e culturais, reflexões acerca da construção discursiva da identidade do indígena sul-mato-grossense nos textos do "Estatuto do Índio" e da "I Conferência Regional dos Povos Indígenas de Mato Grosso do Sul”. O livro, fruto do pós-doutoramento da autora, de suas inúmeras incursões pelos entremeios do discurso, e objeto desta resenha, vem enriquecer o limitado arcabouço teórico que busca preservar a cultura e a identidade indígena, ao lançar seu olhar, não apenas pelo viés da preservação, mas, especialmente pelo viés do reconhecimento desses indivíduos como seres humanos que são.

O livro divide-se em três capítulos principais, intitulados: (1) A imagem que os órgãos oficiais fazem do indígena de Mato Grosso do Sul, dos discursos ditos de inclusão social; (2) As estratégias de produção de verdades pelo poder público: Questões territoriais do povo indígena; (3) Entre-lugares: o entre-tempo-espaço e as entrelínguas, nos quais a autora, sob a perspectiva da Análise do Discurso de linha Francesa, ancorada especialmente nas teorias foucaultianas e derridianas, traz à baila a necessidade de problematizar o discurso

1. Mestranda em Estudos Linguísticos na Universidade Federal de Mato Grosso do Sul. 
normalizador do Estatuto. A partir de uma análise bifurcada que investiga tanto a imagem que os órgãos oficiais fazem do indígena de Mato Grosso do Sul quanto as estratégias de produção de verdades pelo poder público, no tocante às questões territoriais dos povos indígenas, a analista desvela a opacidade e equivocidade da linguagem utilizada pelo discurso oficial.

No capítulo inicial intitulado - A imagem que os órgãos oficiais fazem do indígena de Mato Grosso do Sul, dos discursos ditos de inclusão social - a autora faz uma retrospectiva dos acontecimentos do movimento indigenista brasileiro, na ânsia de apresentar a maneira com a qual o discurso oficial, respaldado pelas regularidades dos discursos de "cidadania”, "inclusão social” e "emancipação", tem preparado armadilhas para os povos indígenas, colocando-os em um entre-lugar.

A autora atenta-nos para o fato de que as diferentes concepções acerca do que é ser índio, por vezes ligadas à ascendência, outras voltadas à questão da consciência da identidade indígena, e, comumente associada ao "primitivo", estão dificultando aos povos indígenas, já distantes do padrão selvagem e mais "urbanizados", o direito de impor sua indianidade à sociedade e ao Estado, que, metodicamente, desrespeita esse direito de auto-identificação. Ao trazer esses questionamentos à tona, Guerra afirma a necessidade de um espaço étnico legitimado, que englobe a complexidade e a pluralidade dos povos indígenas e, ainda, aponta as mudanças sociais ocorridas no sentido de retirar o estereótipo do índio como "incapaz" e subserviente, inscrito na memória social, e apresentá-lo como cidadão, com modos de ser e culturas diferentes.

Dessa maneira, Guerra nos mostra que a questão da inclusão e exclusão, de determinados grupos sociais, está umbilicalmente ligada à criação de um campo de identidades homogêneas, de modo que aquelas pessoas, cujo perfil não se encaixe no tipo de sujeito requerido pelo projeto da pós-modernidade, ficarão submissas aos trâmites de uma lei que os exclui. Nesse contexto, a autora mobiliza o conceito de poder disciplinar, proposto por Foucault, que caracteriza hierarquicamente as sociedades e as instituições modernas, e o de desconstrução, de Derrida, para problematizar a relação entre o 
sujeito e o objeto que a integram, com o intuito de problematizar essa ilusão do sujeito de discurso consciente e detentor da verdade.

No segundo capítulo - As estratégias de produção de verdades pelo poder público: questões territoriais do povo indígena - a autora traz três tópicos principais que demonstram o caminho analítico percorrido, a partir de uma representação das condições de produção do discurso indígena que considera tanto as formações discursivas quanto as ideológicas. No primeiro tópico, desse capítulo, intitulado "O Estatuto do Índio”, a autora desestabiliza os mecanismos utilizados pelo discurso oficial para arregimentar suas normas em relação à demarcação e registro das terras indígenas ocupadas e, para isso, movimenta conceitos distintos e complementares, como a noção de arquivo, de Foucault (1969), a noção de différance, de Derrida (1975), e a noção de hospitalidade, de Derrida (2003).

Em seguida, a analista revela a maneira subversiva com a qual o "Estatuto do Índio" (1973) vem regular a situação jurídica dos índios e das comunidades indígenas, com o hipotético propósito de preservar sua cultura e integrá-los à sociedade nacional. Essa problematização do discurso oficial vem mostrar a legislação como uma estratégia permanente de controle sobre as lutas pela terra. Nesse contexto, de acordo com Guerra, a lei apresenta-se como sintoma das contradições sociais que configuram a sociedade em diversas práticas de resistências. O olhar criterioso das análises nos mostra como os enunciados do Estatuto abalizam as marcas da exclusão, e ratifica o quão são contestados os direitos e as garantias dos povos das comunidades indígenas, na medida em que são tratados como sujeitos de segunda classe.

De acordo com Guerra, o poder exercido por meio do discurso normalizador do Estatuto vem demarcar lugares fixos para os indígenas criarem e desenvolverem suas identidades, de modo que apenas uma consiste a referência, e as demais, a diferença. Verificamos, assim, que o Estatuto, ao invés de garantir aos indígenas os direitos para que estes indivíduos tenham a possibilidade de integrar efetivamente a sociedade nacional, ao contrário, vem limitar os espaços territoriais e controlar as ações das comunidades indígenas. Nesse sentido, o sujeito indígena está 
sempre em um entre-lugar, nem indígena nem cidadão, "em um sempre outro".

Já no segundo tópico - O discurso da I Conferência Regional dos Povos Indígenas de Mato Grosso do sul - por sua vez, a autora trata das questões concernentes ao discurso da "I Conferência Regional dos Povos Indígenas”, realizada em Dourados (MS), em 2005, que buscava, dentre outros objetivos, iniciativas para garantir ao povo indígena a demarcação, homologação e registro das terras indígenas pelo governo federal. No decorrer das análises, Guerra legitima que as materialidades linguísticas dos textos finais da Conferência apontam, de um lado, para uma crítica velada às omissões do Estado; e de outro, para o não comprometimento das postulações do Estatuto. O discurso da Conferência não é o do saber/poder como o do Estatuto, mas sim o de reivindicação e/ou de exigência, apesar do parcial silenciamento do aspecto cultural, sempre mascarado pelo discurso da inclusão.

O cerne dessa questão, na ótica de Guerra, está no fato de que as transformações nos pilares sociais, políticos e culturais da sociedade implicam documentos destinados a romper experiências anteriores à contemporaneidade e altear o discurso da igualdade, da redução das diferenças. Dessa maneira, o discurso do Estatuto rompe com todas as questões sociais e culturais que permeiam a questão da terra para os indígenas ao promulgar um discurso que privilegia o capitalismo, em uma padronização das massas, por meio de verdades formatadas que mobilizam sentidos que burlam a cultura tradicional indígena e desestabiliza as redes de memórias e as filiações históricas que cerceiam a questão da luta pela terra no Brasil. Nas palavras da autora, o Estado se apropria do discurso liberal econômico e reverte suas categorias fundamentais ao representar o índio como cidadão livre e produtor legalizado, colocando o índio como estrangeiro em sua própria terra e língua, posto que precisa da intervenção do branco para legalizar sua existência e a ocupação das suas terras.

Neste contexto, ao movimentar noções como história, memória, biopoder, biopolitica, silêncio, desconstrução e hospitalidade, Guerra (re)afirma a necessidade de desconstruir esses discursos 
oficiais que promulgam lei, cidadania e justiça como sinônimos. O arcabouço teórico definido pela autora permite analisar a variedade de argumentos que sustentam as relações de inclusão/exclusão e exclusão/dominação e reconhecer que a manutenção da dinâmica social está condicionada a um sistema sócio-econômico mundial que "exige a exclusão".

No terceiro tópico denominado - As representaçóes da imagem do índio e as suas (im)possibilidades históricas - os trechos apresentam a voz do índio, via jornal "O Progresso", de Mato Grosso do Sul, com o propósito de mostrar as estratégias de produção e de reprodução das diferentes imagens do índio de Mato Grosso do Sul, considerando a posição privilegiada do jornal, bem como suas funções tanto de porta-voz da sociedade quanto de difusor de ideias e saberes na região.

Ao tomar os conceitos de identidade, de hibridismo, ao desestabilizar a regularidade imediata da palavra "integração" e ressaltar a heterogeneidade dos discursos, Guerra reforça suas considerações acerca do discurso silenciador do Estatuto, tendo em vista que os textos jornalísticos, ao trazerem o discurso do índio, revelam significações com valores culturais e projeções positivas que se opõem às representações capitalistas construídas pelo discurso oficial.

Os trechos jornalísticos apresentados pela pesquisadora corroboram o embate de identidades e de representações marcadas, especialmente, pela associação dispare das denominações: índio versus bugre, que tendem a assentar o índio em um entre-lugar, em um entre-línguas e, ainda, limitar sua participação social como cidadão. A partir da premissa foucaultiana, de que saber é poder, Guerra ratifica e questiona a fabricação de verdade do Estado, que, na ânsia de garantir a inquestionável autoridade e a hegemonia de colonizador, tenta impedir que as minorias constituam, na sociedade, trincheiras de resistência, uma vez que esses sujeitos são continuamente segregados e emudecidos, prostrados à condição de subalternos em um perene balbucio.

No terceiro capítulo - "Entre-lugares: o entre-tempo-espaço e as entre-linguas" - a autora ratifica a hipótese inicial do trabalho ao 
confirmar que alguns povos indígenas são capazes de se perceberem como membros de seu país, de modo que suas condições de vida sejam vistas como consequência da própria participação pública. Entretanto, por outro lado, conclui-se que o texto da Conferência, no qual se esperava ouvir a voz do indígena reivindicando seu lugar social, emerge também como um discurso formatado e normalizador que, semelhante ao discurso da lei do Estatuto, controla, silencia e propõe uma "integração" às avessas do índio e de sua cultura, por meio de uma aculturação unilateral.

Em consonância com as proposições iniciais, Guerra questiona o conceito de cidadania que abarca a questão indígena já que esses sujeitos não podem comungar nem língua nem história com os nacionais. Na ótica da autora, os sentidos de cidadania, justiça e identidade estendem-se a um feixe de manifestações e pressões sociais exercidas pelos grupos na defesa de seus interesses e na legitimação de seus valores, e, dessa maneira, não podem limitar-se a condição de acabados ou, meramente, a relações oficiais. Por fim, Guerra nos leva a concluir que a voz mobilizada pela mídia e pela história mostra que o índio que fala procura ter voz, porém continua apenas balbuciando, e não hesita em apropriar-se da voz do branco para manter-se no espaço social reservado a ele, repleto de restrições.

Com a conclusão da obra, que aborda a questão indígena pelo viés discursivo de maneira ímpar, Guerra convida os pesquisadores, professores, estudantes, governantes e representantes da questão indígena a fazerem uma (re)leitura da problemática questão da luta pela terra no Brasil, e nesse processo, desestabilizarem essa aparente normalidade que se vê em silenciar as populações indígenas, e as minorias, de um modo geral. A obra nos instiga a abandonarmos essa incessante e excludente busca pela hegemonia cultural e assumirmos o babélico espaço do qual somos integrantes, desvendando a equivocidade do discurso.

Recebido em: maio de 2010 Aprovado em: junho de 2010 bethfavero@hotmail.com 